\title{
The Effect of Community-Based Parent Education Program on Parenting Stress According to Adult Attachment Styles
}

\author{
Na Ri Kang ${ }^{1}$, Do Hoon Kim², and Young Sook Kwack ${ }^{1}$ \\ ${ }^{1}$ Department of Psychiatry, Jeju National University School of Medicine, Jeju, Korea \\ ${ }^{2}$ Department of Psychiatry, Kyungpook National University Hospital, Daegu, Korea
}

\begin{abstract}
Objectives: The aim of this study was to measure the effect of a group-based parent education program on parenting stress and attitude and comparing the same according to adult attachment styles.

Methods: Twenty-two mothers who enrolled in the parent education program participated in our study. The participants filled in the Korean version of the Experience in Close Relationship Revised (ECR-R), Korean-Parenting Stress Index-Short Form (K-PSI-SF), Maternal Behavior Research Instrument (MBRI), and Symptom Checklist-90-Revised (SCL-90-R) before and after the program. We compared the pre - and post-scores of the groups and compared the differences in effect according to adult attachment styles.

Results: For all study participants, the Parent Distress $(\mathrm{p}=0.023)$ and Total Parenting Stress $(\mathrm{p}=0.018)$ significantly declined after the parent education program. There were no differences in other variables. Within the secure attachment group, the Total Parenting Stress ( $\mathrm{p}=$ 0.008), Parent Distress ( $\mathrm{p}=0.015)$, and Difficult Child $(\mathrm{p}=0.011)$ scores in the K-PSI-SF significantly decreased after participating in the program. The Difficult Child scores $(\mathrm{p}=0.040)$ significantly dropped in the K-PSI-SF post program within the secure attachment group, compared to the insecure attachment group.

Conclusion: The group-based parent education program impacted parenting stress. Depending on the adult attachment styles, the effect of the program varied.
\end{abstract}

Key Words: Parent education program; Parenting stress; Adult attachment style.

Received: July 15, 2019 / Revision: August 29, 2019 / Accepted: September 16, 2019

Address for correspondence: Young Sook Kwack, Department of Psychiatry, Jeju National University School of Medicine, 15 Aran $13-$ gil, Jeju 63241, Korea Tel: +82-64-717-1850, Fax: +82-64-717-1849, E-mail: yskcpy@jejunu.ac.kr

\section{INTRODUCTION}

Parent-child interactions are important for the psychosocial development of children. Parenting stress negatively affects parenting attitude which might adversely impact such interactions.

Parenting attitude is the general attitude and behaviors of caregivers towards parenting their children for their growth and development. It reflects the values and beliefs of parents and is influenced by the family's social and economic status, and the personal and environmental factors of parents and children [1]. Parenting stress refers to the stress that parents experience in the process of parenting their children because of their child's or their own characteristics. It is a repetitive occurrence of daily life [2].

Pre-existing parent education programs included elements providing information about parenting skills to help improve parents' understanding of their child and positive parenting

This is an Open Access article distributed under the terms of the Creative Commons Attribution Non-Commercial License (https://creativecommons.org/licenses/by-nc/4.0) which permits unrestricted non-commercial use, distribution, and reproduction in any medium, provided the original work is properly cited. roles. Previous studies reported parenting education or parental training programs to reduce parenting stress [3], and promote parenting skills $[4,5]$. However, most programs target parents whose children exhibit or are at risk of behavioral, emotional, and social difficulties. Hence, there is a recently growing interest in the development of universal programs in addition to target programs. The universal parenting program can be an important approach towards preventing mental health problems prior to selective approaches because it can support both, the parents who want to promote their children's well-being in the population-level, as well as parents of high-risk children through public health intervention. One of the previous studies reported on group-based parent education program using the universal approach in communities [6,7]. Recent evidence-based parenting program in the UK communities resulted in reduced problematic behavior [8] and improved parenting efficacy [9].

Attachment theory terms individual's self-perception and of the world, "internal working models." These develop during infancy as a prototype attachment style, guiding their expectations and behavior regarding other close relationships, 
especially with their children. Thus, attachment security developed and experienced in the form of parental attachment in relation to one's parents, has an important influence on a child's parenting behavior [10]. Previous studies classified adult attachment types into: secure, dependent, rejected, and fearful [11]. The secure type was associated with positive parenting such as high parental sensitivity, responsiveness and supportiveness, less parenting stress, and stronger feelings of closeness with children [12]. On the other hand, insecure adult attachment showed a significant association with parenting stress. Parents with insecure attachment, high avoidance, and anxiety showed higher parenting stress [13], hostile attitude towards their children [14], less warmth, closeness, and support [15]. Since the adult attachment type of parents affects parenting behavior and attitude, the effects of parenting education program will be different depending on their attachment type.

Therefore, this study was designed to investigate the effects of parent education program on community parents. We provided a program that included normal developmental processes, communication skills, and information about coping with problems, such as learning difficulty, peer relation problem, school violence. We analyzed the effects of the program and compared them according to the adult attachment security.

\section{METHODS}

\section{Participants and procedures}

The study participants were recruited from among the participants in a parent education program conducted by the Jejusi Mental Health Center in ten sessions from March 22 to December 20,2016. The study participants were asked through questionnaires about their demographic information, scale of parenting stress, parenting style, and adult attachment types before beginning the program. The same questionnaires were filled in after the program's final session. Twenty-two participants were recruited for the study and $50 \%$ of them were 36 to 40 years old. All participants were fully informed about the study protocol. They provided us with their signed, written statements of informed consent. The Institutional Review Board of the Jeju National University Hospital (Grant No. 2018-11002) approved the study.

\section{Program composition and progress}

All program sessions were conducted by five child psychiatrists in the community and were held at the Jejusi City Mental Health Center. In addition to psychosocial development, communication skills, coping with problem behaviors, attention deficit hyperactivity disorder (ADHD), learning prob- lems, peer relationship problems, and other mental health problems that can be experienced during adolescence were included. The topics covered in the program are listed in Table 1.

\section{Measures}

\section{Korean version of Experiences in Close Relationship- Revised (ECR-R)}

The Experiences in Close Relationship-Revised is a measure of one's attachment style to significant others. It consists of 36 items, divided into 2 subscales: attachment anxiety and attachment avoidance. Attachment anxiety is the level of alertness to rejection and abandonment from others, and attachment avoidance is the discomfort in relation to being close to or dependent on others. Each subscale consists of 18 items, indicating the degree of avoidance and anxiety attachment, respectively. Each item is rated on a 7-point Likert scale. All participants were asked to fill in the Korean-version of the ECR$\mathrm{R}$. The Cronbach's alpha score of the attachment anxiety was 0.89 , and attachment avoidance was 0.85 [16]. In this study, we classified the attachment style as a combination of the avoidance and anxiety dimensions based on the average score (Fig. 1). The secure attachment group was defined as the group with lower than the average score on both subscales, and the other three (preoccupied, dismissing-avoidant, and fearful-avoidant) were classified as the insecure attachment group.

\section{Korean-Parenting Stress Index-Short Form (K-PSI-SF)}

The Korean-Parenting Stress Index-Short Form is a measure of the parenting stress experienced by a parent. It consists of the total stress and three subscales: parent distress,

Table 1. Parent education program schedule

\begin{tabular}{|c|c|}
\hline $\begin{array}{l}\text { Session number } \\
\text { (date) }\end{array}$ & Subjects of program \\
\hline $1(2016.3 .22)$ & Development of infant \\
\hline $2(2016.4 .26)$ & Development of adolescent \\
\hline $3(2016.5 .25)$ & About adolescent ADHD \\
\hline $4(2016.6 .23)$ & $\begin{array}{l}\text { Psychiatric problems of children and } \\
\text { adolescents }\end{array}$ \\
\hline $5(2016.7 .19)$ & $\begin{array}{l}\text { Physical management of children and } \\
\text { adolescents }\end{array}$ \\
\hline $6(2016.8 .23)$ & How to cope with school violence? \\
\hline $7(2016.9 .20)$ & How to study well \\
\hline 8 (2016. 10. 20) & $\begin{array}{l}\text { How to develop communicate skills with } \\
\text { your child }\end{array}$ \\
\hline $9(2016.11 .22)$ & $\begin{array}{l}\text { Dealing with behavior problem and } \\
\text { effective rewarding }\end{array}$ \\
\hline $10(2016.12 .20)$ & $\begin{array}{l}\text { Helping children's relationship skill \& } \\
\text { program closing }\end{array}$ \\
\hline
\end{tabular}

ADHD: attention-deficit/hyperactivity disorder 


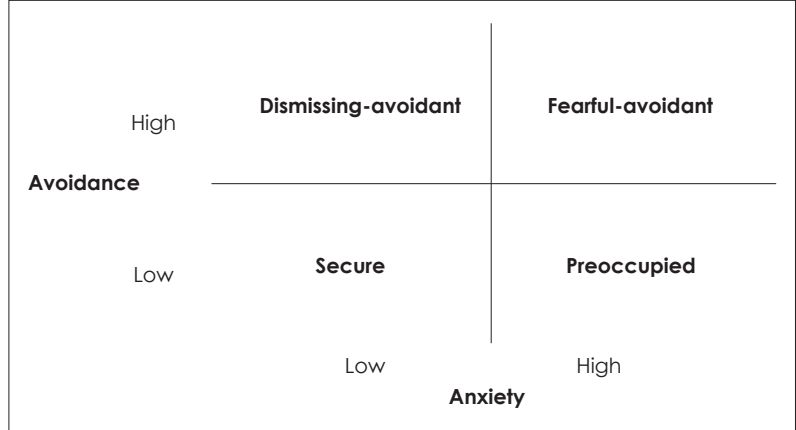

Fig. 1. Model of adult attachment style.

parent-child dysfunctional interaction, and difficult child. The scale consists of total 36 items with 12 items for each subscale. Each item is rated on a Likert scale ranging from one to five (1="not at all," 5 ="present and marked"). Higher scores indicate higher parenting stress. The Cronbach's alpha score of each subscale was $0.79-0.91$, and subscales showed significant discriminative validity $(\mathrm{t}=4.17, \mathrm{p}<0.001)$ [17].

\section{Maternal Behavior Research Instrument (MBRI)}

The Maternal Behavior Research Instrument is a self-report scale that measures parenting attitude. Four parenting attitude types can be defined with this scale: autonomous, controlling, affectionate, hostile. A total 47 items are included. Each question is rated on a scale of one to five, with subscale scores ranging from 12-60 (hostile type: 11-55). The higher the score, the more the mother displays a particular type of parenting attitude. All participants were asked to fill in the Korean version of the MBRI. The Cronbach's alpha was 0.74 for the total scale and internal consistency estimates for the individual subscales were: affectionate, 0.68 ; rejecting, 0.66; autonomy, 0.77; and control, 0.73 [18].

\section{Symptom Checklist-90-Revised (SCL-90-R)}

The symptom checklist-90-revised is a self-report scale that evaluates various psychiatric symptoms along with the general mental health. The scale consists of nine symptom dimensions (somatization, obsessive-compulsion, interpersonal sensitivity, depression, anxiety, hostility, phobic anxiety, paranoid ideation, psychoticism) and 90 items. Each item represents one psychiatric symptom, and the symptoms experienced during the past seven days are scored. Participants rate their responses on a five points scale from zero ("no problems") to four ("very severe"). Higher scores on each dimension indicate the severity of suffering from the symptoms. Standardized Korean versions were used [19].

\section{Statistical analyses}

All statistical analyses were performed using SPSS 23.0 for
Table 2. Socio-demographic characteristics of subjects

\begin{tabular}{lc}
\hline \multicolumn{1}{c}{ Classification } & All subjects \\
\hline Gender & $22(100)$ \\
Female & \\
Age (years) & $1(4.6)$ \\
Below 35 & $11(50)$ \\
$36-40$ & $10(45.4)$ \\
Above 41 & \\
Education & $5(22.7)$ \\
High school & $17(77.3)$ \\
University & \\
Monthly income (million won) & $4(18.2)$ \\
Below 200 & $12(54.5)$ \\
$200-300$ & $6(27.3)$ \\
Above 300 & $12(54.5)$ \\
Children is currently receiving psychiatric treatment \\
Yes \\
No & $10(45.5)$ \\
Presence of physical illness or disability & $3(13.6)$ \\
Yes & $19(86.4)$ \\
No & $2.09(0.68)$ \\
Average number of children, Mean (SD) & \\
\hline Values are presented as $n$ (\%) unless otherwise indicated. SD: \\
standard deviation
\end{tabular}

Windows (IBM Corp., Armonk, NY, USA), and the significance level was set at $\mathrm{p}<0.05$. We analyzed group difference in pre-test scores according to attachment security using the independent $t$-test for continuous variables. Paired $t$-test and Wilcoxon Signed-Rank test were performed to analyze the presence of differences before and after the program in all the participant groups. Further, analysis of covariance (ANCOVA) was used to analyze differences in the pre- and post-test scores according to adult attachment security in the pre-test score and variables showing significant differences between groups were controlled.

\section{RESULTS}

\section{Sociodemographic characteristics of the participants}

The 22 participants were mothers. Their age groups included 36 to 40 years (50\%), over 41 years (45.4\%), and under 35 years (4.6\%). Most of them were college graduates (77.3\%), and five $(22.7 \%)$ graduated from high school. The household income was the highest ranging from two to three million won for 12 (54.5\%) of them. Among all the participants, 12 (54.5\%) participants' children were undergoing psychiatric treatment, and three (13.6\%) had children with physical illnesses. The study participants had an average of 2.09 children with the average age of $7.94 \pm 4.42$ years (Table 2). 
Comparison of pre-test scores of K-PSI-SF, SCL-90-R, and MBRI according to adult attachment security

Of the total participants, 9 were in the secure attachment group and 13 in the insecure attachment group. There were no significant differences in the K-PSI-SF and SCL-90-R between the two groups. The secure attachment group was significantly more autonomous $(\mathrm{p}=0.043)$, and affectionate $(\mathrm{p}=$ 0.043 ) regarding the parenting attitude (Table 3 ).

\section{Difference in pre- and post-test scores for all participants}

Total parenting stress $(\mathrm{p}=0.018)$, parental distress $(\mathrm{p}=0.023)$ in the K-PSI-SF were significantly reduced after the parent education program. There were no significant differences in the parenting attitude and attachment scores before and after the program (Table 4).

\section{Difference in pre- and post-test scores according to adult attachment security}

Within the secure attachment group, there was a significant decrease in the parental distress $(\mathrm{p}=0.015)$, difficult child $(\mathrm{p}=0.011)$, and total parenting stress $(\mathrm{p}=0.008)$ after the program. There were no significant differences in the variables between before and after the program in the insecure attach- ment group. Like the ANCOVA result of adjusting the "autonomous" and "affectionate" parenting attitude scores showed significant differences between the groups and pre-test scores, it was found that the difficult child $(\mathrm{p}=0.040)$ in the K-PSISF significantly decreased in the secure attachment group than the insecure attachment group (Table 5).

\section{DISCUSSION}

In this study, the parent education program was observed to have a significant effect by reducing parenting stress. In the secure attachment group, the parenting stress showed a significant decline after the parent education program, and the stress in terms of the "difficult child" also significantly decreased compared to the insecure attachment group.

Previous studies reported that parents education programs for parents of elementary school students had a significant effect on parent distress, parent-child dysfunctional interaction, and difficult child of parenting stress by broadening the psychological understanding of their child. This is consistent with our study results [20].

However, this study did not show significant effects of the parent education program on parenting attitude. This is different from the results of previous studies wherein the parent

Table 3. Baseline characteristics of parent reported scale according to adult attachment style

\begin{tabular}{|c|c|c|c|c|}
\hline & $\begin{array}{l}\text { Secure attachment } \\
\text { group }^{\dagger}(n=9)\end{array}$ & $\begin{array}{c}\text { Insecure attachment } \\
\text { group }^{\dagger}(n=13)\end{array}$ & Z & $\mathrm{p}$ \\
\hline \multicolumn{5}{|l|}{ Parenting stress (K-PSI-SF) } \\
\hline Parent distress & $33.44(7.98)$ & $35.46(5.58)$ & -0.737 & 0.471 \\
\hline Parent-child dysfunctional Interaction & $26.44(9.58)$ & $30.77(7.14)$ & -1.372 & 0.186 \\
\hline Difficult child & $35.00(10.32)$ & $38.46(8.92)$ & -1.037 & 0.324 \\
\hline Total parenting stress & $94.898(22.72)$ & $104.69(16.39)$ & -1.471 & 0.144 \\
\hline \multicolumn{5}{|l|}{ Psychopathology (SCL-90-R) } \\
\hline Somatization & $47.44(6.80)$ & $42.15(5.47)$ & -1.641 & 0.110 \\
\hline Obsessive-compulsive & $49.33(9.85)$ & $46.61(7.60)$ & -0.637 & 0.556 \\
\hline Interpersonal sensitivity & $46.22(8.11)$ & $47.15(7.07)$ & -0.369 & 0.744 \\
\hline Depression & $45.78(7.19)$ & $45.77(7.67)$ & -0.369 & 0.744 \\
\hline Anxiety & $43.89(6.68)$ & $42.46(5.22)$ & -0.471 & 0.637 \\
\hline Hostility & $51.44(11.72)$ & $46.15(5.43)$ & -1.009 & 0.324 \\
\hline Phobic anxiety & $43.89(4.14)$ & $44.23(5.53)$ & -0.036 & 1.000 \\
\hline Paranoid ideation & $46.22(6.72)$ & $42.46(5.01)$ & -1.398 & 0.186 \\
\hline Psychoticism & $43.67(4.50)$ & $42.54(4.33)$ & -0.576 & 0.601 \\
\hline Total score & $45.11(7.75)$ & $42.69(6.02)$ & -1.038 & 0.324 \\
\hline \multicolumn{5}{|l|}{ Parenting type (MBRI) } \\
\hline Autonomous & $43.11(7.24)$ & $37.46(4.63)$ & -2.042 & $0.043^{*}$ \\
\hline Controlling & $37.00(8.22)$ & $35.23(4.49)$ & -1.237 & 0.235 \\
\hline Affectionate & $46.22(5.80)$ & $39.77(6.81)$ & -2.010 & $0.043^{*}$ \\
\hline Hostile & $31.22(7.59)$ & $36.00(5.39)$ & -1.681 & 0.093 \\
\hline
\end{tabular}

Values are presented as mean (standard deviation) unless otherwise indicated. ${ }^{*} p<0.05$, ${ }^{\dagger}$ Wilcoxon Signed-Rank test. K-PSI-SF: Korean-Parenting Stress Index-Short Form, MBRI: Maternal Behavior Research Instrument, SCL-90-R: Symptom Checklist-90-Revised 
Table 4. Comparison between pre and post-intervention score after parenting program in the whole group

\begin{tabular}{|c|c|c|c|c|}
\hline & Pre $(n=22)^{\dagger}$ & Post $(n=22)^{\dagger}$ & Z & $P$ \\
\hline \multicolumn{5}{|l|}{ Parenting stress (K-PSI-SF) } \\
\hline Parent distress & $34.63(6.56)$ & $31.59(7.77)$ & -2.268 & $0.023^{*}$ \\
\hline Parent-child dysfunctional interaction & $29.00(8.29)$ & $27.63(10.02)$ & -1.273 & 0.203 \\
\hline Difficult child & $37.04(9.43)$ & $34.86(9.92)$ & -1.703 & 0.088 \\
\hline Total parenting stress & $100.68(19.35)$ & $94.0(24.59)$ & -2.364 & $0.018^{*}$ \\
\hline \multicolumn{5}{|l|}{ Parenting type (MBRI) } \\
\hline Autonomous & $39.77(6.34)$ & $41.04(5.71)$ & 1.334 & 0.182 \\
\hline Controlling & $35.95(6.16)$ & $36.13(6.19)$ & 0.358 & 0.720 \\
\hline Affectionate & $42.40(7.06)$ & $42.18(7.68)$ & -0.285 & 0.775 \\
\hline Hostile & $34.04(6.65)$ & $32.63(7.16)$ & -1.238 & 0.216 \\
\hline \multicolumn{5}{|c|}{ Experiences in Close Relationship-Revised (ECR-R) } \\
\hline Attachment avoidance & $3.49(1.02)$ & $3.60(0.90)$ & 0.305 & 0.760 \\
\hline Attachment anxiety & $3.12(0.90)$ & $3.18(1.20)$ & 0.663 & 0.507 \\
\hline
\end{tabular}

Values are presented as mean (standard deviation) unless otherwise indicated. ${ }^{*} p<0.05$, ${ }^{\dagger}$ Wilcoxon Signed-Rank test from pre- to post-intervention on parent reported measures. K-PSI-SF: Korean-Parenting Stress Index-Short Form, MBRI: Maternal Behavior Research Instrument

education program had a positive effect on parenting attitude $[21,22]$. This may be due to differences in the composition of the programs, some of which are programs designed to teach active parenting skills such as Active Parenting Training (APT) program [23]. However, the program used in this study had comprehensive contents such as, child's development and specific knowledge about mental health problems rather than direct contents about parenting attitude. In the future, it will be necessary to consider the contents of specific parenting skills to influence parenting attitude.

The important finding of this study is that the effects of parent education program differed depending on the type of adult attachment. In this study, psychopathology and parenting stress were not significantly different according to the attachment security, but the decreased parenting stress of "difficult child" after the program was much greater in the secure attachment group. Previous studies have shown similar results wherein the higher the level of anxious/ambivalent attachment, the lesser the positive effects of social support on parental interactions [24]. Additionally, parents of the insecure attachment group with high avoidance and anxiety scores reported higher parenting stress [12], and more negatively perceived their child's temperament $[25,26]$. The high attachment-avoidance scores were associated with low positive expectations from their child [27]. The results of this study suggest that the parent's perception is easily changed by universal approaches such as group-based parent education. Considering that parents with insecure adult attachment are more likely to accept perceptions of children as difficult or accept them negatively, the results of this study suggest that parents' perception is unlikely to change with a universal approach to parent education program. It is necessary to con- sider parental adult attachment style when constructing interventions such as parent education or parent training programs.

This study has several limitations. Despite voluntary participation through open recruitment without limiting the children's age and specific mental health problems, the participants were small in number and more than $50 \%$ of the children were undergoing psychiatric treatment. This could entail selection bias, limiting its generalization to the general population. Further, there was no randomization to the intervention and comparison groups. In addition to parent education programs, there are various factors affecting parenting stress and attitude change, but this study did not entirely consider variables such as the child's temperament and mental health related factors. We did not identify changes in the child's emotions and behavior due to the effects of parent education program, neither could we compare the effects of the program according to the number of children. Previous studies reported no significant differences in parenting stress according to the number of children [28], but it is necessary to consider the differences in parenting stress and attitudes, effects of the program according to the number of children.

Nevertheless, the strengths of this study lie in depicting the effects of a group-based parent education program conducted in ten sessions over a year, which included comprehensive parenting information and ways to approach a child's mental health problem. Different effects of the program according to the parent's adult attachment style were found, suggesting that different approaches to parent education programs should be considered depending on the adult attachment type of the parent. 


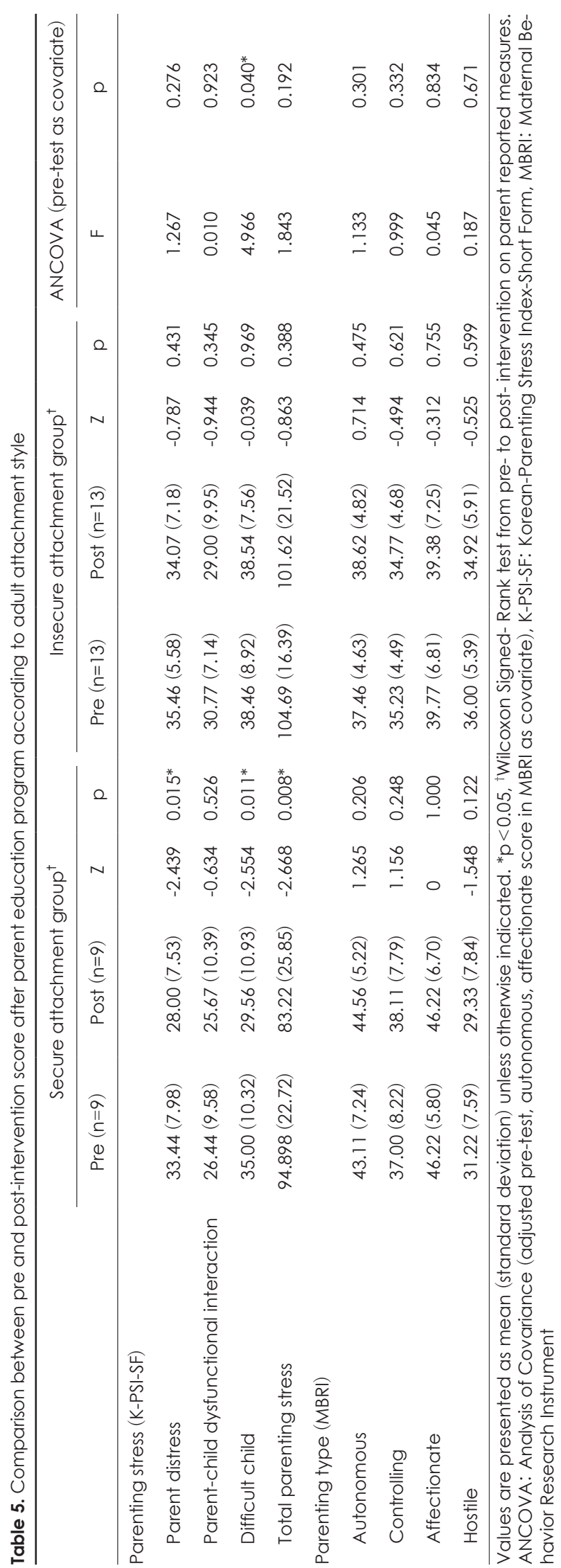

\section{CONCLUSION}

This study indicated that ten sessions of a group-based parent education program have a positive effect of reducing the parenting stress and the effect differed according to the types of adult attachment of the parents. In the future, it is necessary to study the effects of parent education programs on parenting and mental health of children involving a larger number of parents in the community.

\section{Acknowledgments}

This work was supported by the research grant of Jeju National University Hospital development fund (Grand No. 2018-11-002) in 2018.

\section{Conflicts of Interest}

The authors have no potential conflicts of interest to disclose.

\section{Author Contributions}

Data curation: Young Sook Kwack. Formal analysis: Na Ri Kang. Funding acquisition: Young Sook Kwack. Investigation: Na Ri Kang. Methodology: Na Ri Kang. Project administration: Young Sook Kwack. Supervision: Young Sook Kwack. Validation: Do Hoon Kim. Visualization: Do Hoon Kim. Writing—original draft: Na Ri Kang. Writing_review \& editing: Do Hoon Kim.

\section{ORCID iDs}

$\begin{array}{ll}\text { Na Ri Kang } & \text { https://orcid.org/0000-0002-2086-0927 } \\ \text { Do Hoon Kim } & \text { https://orcid.org/0000-0003-1019-8834 } \\ \text { Young Sook Kwack } & \text { https://orcid.org/0000-0002-6071-238X }\end{array}$

\section{REFERENCES}

1) Baumrind D. Current patterns of parental authority. Developmental Psychology 1971;4:1-103.

2) Deater-Deckard K. Parenting stress. New Haven: Yale University Press;2008. p.1-7.

3) Castel S, Creveuil C, Beunard A, Blaizot X, Proia N, Guillois B. Effects of an intervention program on maternal and paternal parenting stress after preterm birth: a randomized trial. Early Hum Dev 2016;103:17-25

4) Scott S, Briskman J, O'Connor TG. Early prevention of antisocial personality: long-term follow-up of two randomized controlled trials comparing indicated and selective approaches. Am J Psychiatry 2014;171:649-657.

5) Wright B, Barry M, Hughes E, Trépel D, Ali S, Allgar V, et al. Clinical effectiveness and cost-effectiveness of parenting interventions for children with severe attachment problems: a systematic review and meta-analysis. Health Technol Assess 2015;19:vii-xxviii, 1-347.

6) Spoth R, Redmond C. Research on family engagement in preventive interventions: toward improved use of scientific findings in primary prevention practice. Journal of Primary Prevention 2000;21: 267-284.

7) Heinrichs N, Bertram H, Kuschel A, Hahlweg K. Parent recruitment and retention in a universal prevention program for child behavior and emotional problems: barriers to research and program participation. Prev Sci 2005;6:275-286.

8) Lindsay G, Strand S, Davis H. A comparison of the effectiveness of three parenting programmes in improving parenting skills, parent mental-well being and children's behaviour when implemented on a large scale in community settings in 18 English local authorities: the parenting early intervention pathfinder (PEIP). BMC Public Health 2011;11:962. 
9) Lindsay G, Totsika V. The effectiveness of universal parenting programmes: the CANparent trial. BMC Psychol 2017;5:35.

10) Cowan PA, Cowan CP, Mehta N. Adult attachment, couple attachment, and children's adaptation to school: an integrated attachment template and family risk model. Attach Hum Dev 2009;11:29-46.

11) Bartholomew K, Shaver PR. Methods of assessing adult attachment. In: Simpson JA, Rholes WS, editors. Attachment theory and close relationships. New York: Guilford Press;1998. p.25-45.

12) Jones JD, Cassidy J, Shaver PR. Parents' self-reported attachment styles: a review of links with parenting behaviors, emotions, and cognitions. Pers Soc Psychol Rev 2015;19:44-76.

13) Moreira H, Gouveia MJ, Carona C, Silva N, Canavarro MC. Maternal attachment and children's quality of life: the mediating role of self-compassion and parenting stress. J Child Fam Stud 2015;24: 2332-2344.

14) Jones JD, Cassidy J. Parental attachment style: examination of links with parent secure base provision and adolescent secure base use. Attach Hum Dev 2014;16:437-461.

15) Edelstein RS, Alexander KW, Shaver PR, Schaaf JM, Quas JA, Lovas GS, et al. Adult attachment style and parental responsiveness during a stressful event. Attach Hum Dev 2004;6:31-52.

16) Kim S. Adaptation of the experiences in close relationships-revised scale into Korean: confirmatory factor analysis and item response theory approaches. Seoul: Seoul National Univ.;2004.

17) Lee KS, Chung KM, Park JA, Kim HJ. Reliability and validity study for the Korean version of parenting stress index short form (K-PSISF). Korean J Woman Psychol 2008;13:363-377.

18) Kim SJ, Kim YH, Kim KS. Mothers' Child-Rearing Attitude. Child Health Nurs Res 2003;9:392-398.

19) Kim KI, Won HT, Lee JH, Kim KY. Standardization study of symptom check list-90 in Korea I: characteristics of normal responses. J
Korean Neuropsychiatr Assoc 1978;17:449-458

20) Kim JH. Effects of the parent education program on parenting efficacy and maternal parenting stress. Busan: Graduate School of Education, Busan National University of Education;2006.

21) Shin SH, Won JS. The effects of a self-esteem enhancement parent education program for mothers with children in elementary school. J Korean Acad Psychiatr Ment Health Nurs 2009;18:492-500.

22) Kim JU, Lee MS. Effects of relationship enhancement parent effectiveness training on parent-child communication, the parenting attitude of parents and children's self-esteem. Korean Journal of East West Science 2009;12:61-76.

23) Mullis F. Active parenting: an evaluation of two Adlerian parent education programs. Individual Psychology 1999;55:225-232.

24) Green BL, Furrer C, McAllister C. How do relationships support parenting? Effects of attachment style and social support on parenting behavior in an at-risk population. Am J Community Psychol 2007;40:96-108.

25) Pesonen AK, Räikkönen K, Strandberg T, Keltikangas-Järvinen L, Järvenpää AL. Insecure adult attachment style and depressive symptoms: Implications for parental perceptions of infant temperament. Infant Ment Health J 2004;25:99-116.

26) Priel B, Besser AV. Adult attachment styles, early relationships, antenatal attachment, and perceptions of infant temperament: a study of first-time mothers. Pers Relatsh 2000;7:291-310.

27) Lenzi D, Trentini C, Pantano P, Macaluso E, Lenzi GL, Ammaniti M. Attachment models affect brain responses in areas related to emotions and empathy in nulliparous women. Hum Brain Mapp 2013;34:1399-1414.

28) Lee MH. Parenting attitude and parenting stress of mothers and fathers by child-related variables. Seoul: Sungshin Women’s Univ.;2016. 